\title{
A CONSTRUÇÃO DE NOVAS NARRATIVAS DE LETRAMENTO: ANÁLISE DE UM EVENTO DO PROJETO SER TÃO POETA ${ }^{1}$
}

\author{
Ariane Samila Ferreira de Oliveira Rosa ${ }^{2}$ \\ Josemar Martins Pinzoh ${ }^{3}$
}

\begin{abstract}
Resumo
O presente trabalho analisa um sarau promovido pelo Grupo Ser Tão Poeta em um shopping center da cidade de Petrolina, PE, com o objetivo de, primeiro, descobrir formas de letramento contextualizadas às necessidades locais, como a criação de narrativas que estão em sentido oposto à cultura de massa, realizada por um grupo de jovens poetas, homens e mulheres, durante um sarau desenraizado do seu espaço de origem; e, segundo, discutir as diversas práticas de letramento envolvidas. A base conceitual do estudo tem como base principalmente Street $(2006 ; 2016 ; 2018)$; Soares (2018); Kleiman (1995). A metodologia utilizada foi um estudo de cunho etnográfico. Conclui-se que é possível a construção de novas proposições de interação escrita e leitura, no âmbito do letramento literário, que levem em consideração outras circunstâncias dos atores envolvidos, através da prática da escrita, dentro das características peculiares de cada proposta de letramento.
\end{abstract}

Palavras-chave: Letramento. Evento de Letramento. Protagonismo Literário. Poesia.

\section{THE CONSTRUCTION OF NEW LETTER NARRATIVES: ANALYSIS OF A PROJECT EVENT TO BE SO POET}

\begin{abstract}
${ }^{1}$ Este estudo foi demandado pela intensidade das problematizações construídas durante a disciplina Políticas de Letramento, ofertada pelo Programa de Pós-Graduação em Educação, Cultura e Territórios Semiáridos (PPGESA) da Universidade do Estado da Bahia (UNEB), que trouxe proposições acerca do letramento, suas práticas e eventos, discutindo em aula suas devidas referências.

${ }^{2}$ Mestranda no Programa de Pós-Graduação em Educação, Cultura e Territórios Semiáridos - PPGESA, UNEB, Campus III. E-mail: arianesescliteratura@hotmail.com.

3 Josemar da Silva Martins, Pinzoh, é Professor Adjunto da UNEB no DCH III, Doutor em Educação, professor do Programa de Pós-Graduação em Educação, Cultura e Territórios Semiáridos - PPGESA. Email: pinzoh@hotmail.com.
\end{abstract}


This paper analyzes a soiree promoted by the Group Ser Tão Poeta in a shopping center in the city of Petrolina, PE, with the objective of, first, discovering ways of literacy that are contextualized to local needs, such as the possibility of creating narratives in opposite to mass culture, such as those performed by a group of young poets, men and women, during a soiree uprooted from their place of origin; and, second, discussing the diverse literacy practices involved. The conceptual basis of the study is mainly based on Street (2006; 2016; 2018); Soares (2018); Kleiman (1995). The methodological approach used was ethnographic. It is concluded that it is possible to construct new propositions of literary writing and reading that take into account other circumstances of the actors involved, through the practice of writing, within the specific characteristics of each literacy proposal.

Keywords: Literacy. Literacy Event. Literary protagonism. Poetry.

\section{CONSTRUCCIÓN DE NUEVAS NARRATIVAS DE LETRAS: ANÁLISIS DE UN EVENTO DE PROYECTO PARA SER TAN POETO}

\section{Resumen}

Este artículo analiza un recital promovida por el grupo Ser Tão Poeta en un centro comercial en la ciudad de Petrolina, PE, con el objetivo de descubrir, primero, formas de alfabetización contextualizadas a las necesidades locales, como la posibilidad de crear narrativas contrarias a la cultura de masas, realizada por un grupo de jóvenes poetas, hombres y mujeres, durante un recital desarraigado de su lugar de origen; y, segundo, discutir las diversas prácticas de alfabetización involucradas. La base conceptual del estudio se basa principalmente en Street $(2006 ; 2016 ; 2018)$; Soares (2018); Kleiman (1995). La metodología utilizada fue un estudio etnográfico. Se concluye que es posible construir nuevas propuestas de interacción escrita y de lectura dentro de la alfabetización literaria, que lleven en cuenta otras circunstancias de los actores involucrados, a través de la práctica de la escritura, dentro de las características peculiares de cada propuesta de alfabetización.

Palabras clave: Alfabetización. Evento de alfabetización. Protagonismo literario. Poesía

\section{Introdução}

Como diz Guattari (1990), apesar de todas as formas de engessamento da subjetividade exercida pelos dispositivos culturais e de comunicação hegemônicos sobre os jovens, esses ainda desenvolvem suas "distâncias de singularização", criam zonas autônomas e contra-hegemônicas de atuação e de produção de valor e de sentido. A ausência de políticas públicas no âmbito cultural também impulsiona jovens artistas a buscarem outras formas de promover ações culturais e comunicar suas criações. Neste 
caso, a diversidade de ações se dá desde as ações realizadas nos seus locais de atuação próprios, como nas sedes dos próprios grupos, como também, cada vez mais, em espaços diversificados, como ruas, praças e shopping centers. Para além do aspecto da diversidade de espaços de atuação, nos interessa aqui vincular tais acontecimentos ao conceito de letramento.

Neste sentido, percebe-se, cada vez mais, que esses eventos e acontecimentos desenvolvem novos tipos de letramentos, na medida em que mobilizam novas experiências de leitura e de escrita, de forma dinâmica. É neste contexto que se situa o trabalho do Projeto Ser Tão Poeta. Assim, analisamos um acontecimento deste projeto, uma récita de poesias num shopping center da cidade de Petrolina, como um evento de letramento.

Pode se entender por evento de letramento um acontecimento específico e situado onde ocorre uma experiência mediada pelo uso concreto da leitura e da escrita. $\mathrm{O}$ evento de letramento compreende elementos observáveis que se dão na interação mediada pela leitura e escrita, sendo essas formas diferentes em diversificados grupos e interesses sociais. Street (2018) argumenta que esses eventos são comuns no dia a dia.

\begin{abstract}
No cotidiano de uma sala de aula, por exemplo, podem ser identificados em situações em que professor e alunos conversam sobre um livro lido pela turma ou sobre uma notícia de jornal comentada por um aluno. $\mathrm{O}$ mesmo ocorre nas situações em que o professor registra no quadro o nome dos aniversariantes, a agenda de trabalho do dia ou os nomes dos alunos 'bagunceiros'. As pessoas também se envolvem em vários eventos de letramento fora da escola quando, por exemplo, participam de um ritual religioso, leem um livro para os filhos, anotam compras em uma caderneta, leem e escrevem cartas e e-mails ou leem pequenos anúncios em busca de emprego (STREET, 2018).
\end{abstract}

Os eventos de letramento, portanto, ocorrem em diferentes espaços sociais e assumem diferentes formas. É perceptível que o letramento não se encaixa em um conceito único e compacto e, conforme Street (2006) um "modelo ideológico" de letramento, por exemplo, compreende a multiplicidade de interações que ocorrem sustentadas por diversas práticas de letramento.

Para Kleiman (1995, p. 38), o modelo ideológico destaca o fato de que "as práticas de letramento são aspectos não apenas da cultura mas também das estruturas de poder numa sociedade". Isso, para a autora, permite que aspectos específicos das práticas de letramento possam "ser examinados relativamente a questões outras que o 
marco divisor entre oralidade e escrita", pois, o pressuposto básico desse modelo é "que as práticas de letramento mudam segundo o contexto.” (KLEIMAN, 1995, p. 39).

Assim, as práticas do grupo estudado, situam-se na perspectiva do "modelo ideológico" de letramento, visto que ele se vale da compreensão das multiplicidades das interações mediadas pela escrita (e pela leitura) e pelo seu uso social - ao contrário do modelo dominante, o "modelo autônomo", que, segundo Street (2006), valoriza uma única forma de compreensão, vinculada aos elementos meramente técnicos do aprendizado e da transmissão do conhecimento.

O evento de letramento que analisamos aqui é promovido pelo Projeto Ser Tão Poeta, organizado por um grupo de jovens poetas da periferia de Petrolina-PE. O projeto foi idealizado em 2014, mas a sistematização das atividades foi iniciada em 27 de julho do ano anterior, 2013. A administração do grupo é composta pela presidência de Graciele Castro e a vice-presidência de Fabrício Nascimento, e tem como principais objetivos despertar o interesse das pessoas da região pela leitura, bem como divulgar a produção literária dos artistas locais de Petrolina e região.

O projeto vem desenvolvendo diversos eventos de letramento que envolvem diferentes práticas, entre os quais podemos citar a realização de saraus em espaços públicos, de feiras literárias, as publicações de cordéis, assim como de oficinas de literatura de cordel em escolas públicas. No que concerne aos eventos de letramento, podemos exemplificar as leituras de poemas que acontecem nos saraus e a escrita de textos poéticos que acontecem durante as oficinas.

O método utilizado no presente estudo consistiu em um estudo de cunho etnográfico. O contato com o grupo Ser Tão Poeta ocorria por cerca de dois anos e incluía o acompanhamento de várias atividades nos eventos (como oficinas, saraus, feiras literárias), havendo ainda a participação de um dos autores do presente artigo num grupo de comunicação direta com os poetas através do aplicativo WhatsApp. Este artigo faz considerações acerca da observação feita durante a realização de um sarau no shopping center da cidade de Petrolina, a primeira vez que o grupo realizou a ação no referido local.

\section{Perspectiva conceitual acerca do letramento}

São diversas as formas de entender os conceitos acerca do letramento. Uma das maiores referências é Brian Street, que aprecia esse conceito de forma ampla, 
entendendo sua variedade e complexidade. Assim, Street escreve sobre as consequências de aquisição do letramento para sociedades inteiras e grupos sociais, sendo necessário, "situar as práticas de letramento no contexto do poder e da ideologia, e não como uma habilidade neutra, técnica" (STREET, 2006, p. 465). O autor apresenta dois modelos que precisam ser levados em consideração para problematizar o "futuro do letramento" e as campanhas de alfabetização e letramento.

O "modelo autônomo", segundo Street (2006) compreende uma direção unilateral em que o desenvolvimento é associado à ideia de progresso, civilização, liberdade individual e mobilidade social, no qual é permitida apenas uma visão que isola o letramento como uma variedade independente; é o modelo seguido por aqueles no poder, que não querem se desvincular de padrões já estabelecidos. Ao contrário disso, um "modelo ideológico", reconhece a multiplicidade de letramentos existentes e a sua natureza ideológica (do ponto de vista dos interesses e posicionamentos dos indivíduos e grupos), culturalmente incrustada nas práticas e considera que há diversificados letramentos que partem das necessidades individuais de cada um (STREET, 2014, p. 44).

Dentro dessa noção de "modelo autônomo", o autor disserta sobre o letramento colonial que consiste na transmissão de valores ocidentais para sociedades não ocidentais; esse letramento transferido de uma cultura para outra é um exemplo de colonização. É o letramento dominante e, como o próprio nome nos leva a deduzir, diz respeito ao domínio de uma cultura por outra, e nem sempre acarreta o significado de "o letramento ser transferido de uma sociedade externa para nativos 'iletrados'. Em muitas situações, é um grupo dominante que se responsabiliza por difundir o letramento a outros membros dessa sociedade e as subculturas dentro dela" (STREET, 2014, p. 45). O modelo "ideológico" de letramento, defendido por Street (2006, p. 466),

reconhece uma multiplicidade de letramentos; que o significado e os usos das práticas de letramento estão relacionados com contextos culturais específicos; e que essas práticas estão associadas com relações de poder e ideologia: não são simplesmente tecnologias neutras.

Assim, o "modelo ideológico" de letramento pode ser um lugar de negociação e de transformação, uma mudança de paradigma na sociedade atual, pelo menos no nível dos interesses, ou seja, o modo pelo qual as pessoas rejeitam e propõem outras posições, ligadas às suas identidades culturais particulares, e não as que lhe são conferidas 
previamente e impostas de fora pra dentro. Street argumenta que, embora exista uma supremacia do letramento dominante sobre outros letramentos, rotulando como inadequados aqueles que não pertencem à cultura propositora ou impostora (palavras nossas); o letramento dominante é uma variedade entre muitas e quem (ou o que) o legitima é uma questão de poder.

Mas, é preciso considerar que a palavra letramento se distingue da palavra alfabetização, e argumentamos, principalmente com base em Soares (2018), que não podemos reduzir a necessidade de aquisição inicial da capacidade de ler e escrever ao que Street chama de "letramento autônomo", embora a maioria das abordagens faça esta equivalência. O nível da alfabetização, que, segundo Soares (2018), situa-se dentro do quadro da "faceta linguística" da aprendizagem inicial da língua escrita, ou seja, da aprendizagem de um sistema de escrita alfabética que é, ao mesmo tempo, um sistema de representação e um sistema notacional, não pode simplesmente ser reduzido ao conceito de letramento autônomo como parece ter virado convenção. No nível da alfabetização, letramento autônomo e letramento ideológico podem conter níveis profundos de interação. ${ }^{4}$

$\mathrm{O}$ esclarecimento e refinamento do conceito de letramento, chama atenção às “distâncias de singularização" (Guattari, 1990) dos jovens, abandonando a dicotomia entre "letrado" e "iletrado", e focalizando as diversas práticas de letramento, em contextos diversificados, "modelos diferentes pelos quais representamos nossos usos e significados de ler e escrever em diferentes contextos sociais [...] e épocas diferentes, demonstrando que é enganoso pensar em uma coisa única e compacta chamada letramento" (STREET, 2006, p. 466).

Portanto, devem ser consideradas outras formas de letramento, com base na variedade, em vez de considerar apenas um modelo único.

\section{Metodologia}

Esse estudo é de cunho etnográfico e, embora o evento aqui descrito refira-se a uma situação específica observada durante um sarau, o contato com o grupo Ser Tão Poeta já é um contato de longo prazo, que já dura uns dois anos. O acompanhamento de

\footnotetext{
4 A questão da alfabetização hoje ocupa amplo e importante lugar na agenda oficial, que luta para melhorar os indicadores de aprendizagem inicial e da capacidade de ler e escrever. Na presente análise, não estamos discutindo a aquisição inicial da escrita e da leitura, por isso mesmo, o termo que aqui predomina é letramento.
} 
diversas de suas atividades, oficinas, saraus, feiras literárias, publicações de cordéis etc., e a participação de um grupo de comunicação direta com os poetas através do WhatsApp são elementos que caracterizam e justificam a perspectiva etnográfica deste estudo.

A situação específica aqui discutida foi observada durante um sarau poético, ocorrido no River Shopping, em Petrolina-PE, na livraria Eu Amo Ler, no dia 4 de maio de 2018 , com uma duração de 5 horas, das 14 h00 às 19 h00. Além da observação deste específico evento, foi realizada, posteriormente, uma entrevista semiestruturada com a presidenta do grupo, partindo de questões básicas previamente elaboradas, mas que foi se adentrando em problemáticas ainda não mencionadas nem antecipadamente previstas, porém de extrema relevância para trabalho. Também utilizamos como instrumentos de coleta e registro de dados a fotografia, o vídeo, e anotações de percepções feitas durante a realização do evento.

Estavam presentes Graciele Castro - presidenta do grupo; Fabrício Nascimento - vice-presidente; Kelmara Vasco - responsável pela divulgação e apoio; e, excepcionalmente para essa intervenção, um convidado, Diêgo Milhomens.

\section{Resultados e discussão: construindo pontes}

A escolha do local não aconteceu de maneira aleatória; a presidenta do grupo tinha como objetivo levar poesias para as pessoas em um ambiente cujo foco estivesse voltado para outras atividades, comerciais, na sua maioria, sendo esta a primeira experiência do grupo em um espaço não convencional para um sarau e, também, a primeira vez que o shopping se disponibilizava para um evento desse tipo. Os desafios começaram desde a entrega do ofício, solicitando o uso do espaço até ao dia da intervenção. 
Fotografia 1: Cartaz de divulgação do evento, 2018

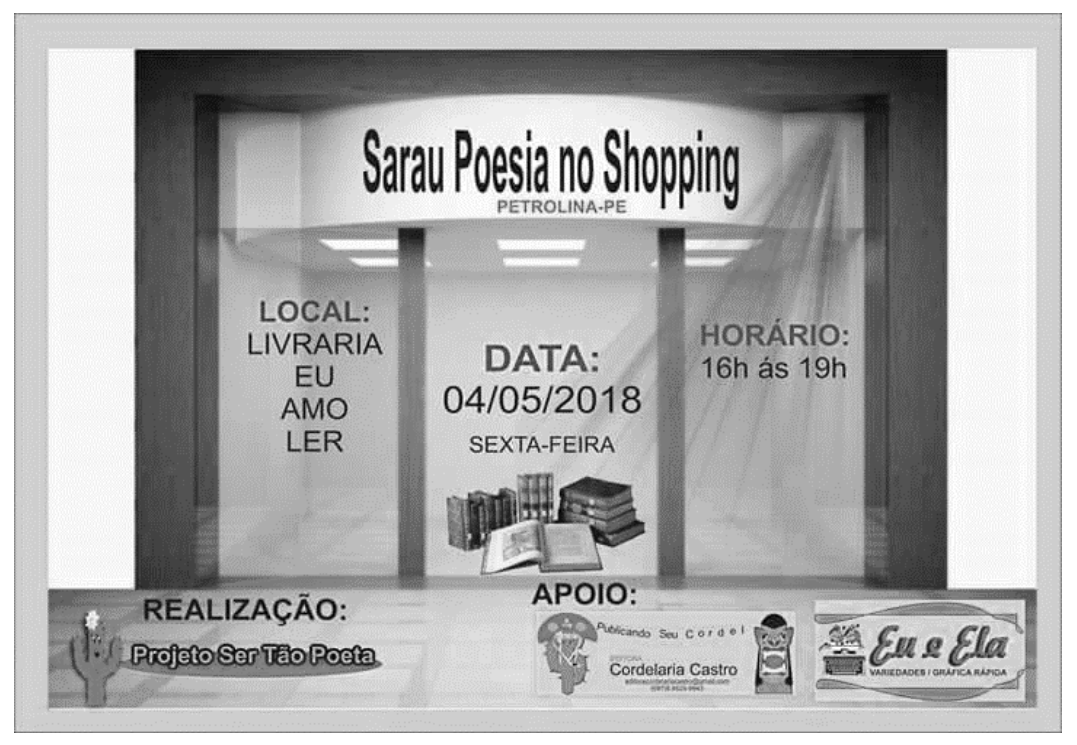

Arte gráfica do evento: Graciele Castro

Dentre os acordos estabelecidos com a livraria, segundo relatou a presidenta, estava o fato de nenhum dos participantes sair do espaço da livraria e abordar os passantes com a récita dos poemas, assim como não utilizar nenhum equipamento sonoro, ficando a projeção dos poemas a cargo da própria voz. A livraria não é uma loja física, seu espaço é constituído de um estande localizado no corredor do shopping, havendo áreas destinadas à locomoção em seus arredores.

Uma minoria dos passantes parava para observar a récita dos poemas, outros, curiosos com a movimentação, aproximavam-se do espaço a fim de perceber o que se passava, sendo essa uma ação voluntária, pois, os/as poetas estavam impossibilitados de se aproximar das pessoas fora do espaço da livraria, e também foram orientados a evitar a aglomeração de mais de seis pessoas no local: a medida para a dispersão partiria da segurança do shopping. Segundo a presidenta do grupo, o objetivo foi cumprido, havendo uma recepção previsível do público, dadas as circunstâncias. Houve desafios, muitas pessoas passavam sem se darem conta da interferência poética naquele espaço, enquanto outras paravam e contemplavam o momento. 
Fotografia 2: momento de acontecimento do sarau no shopping, maio de 2018.

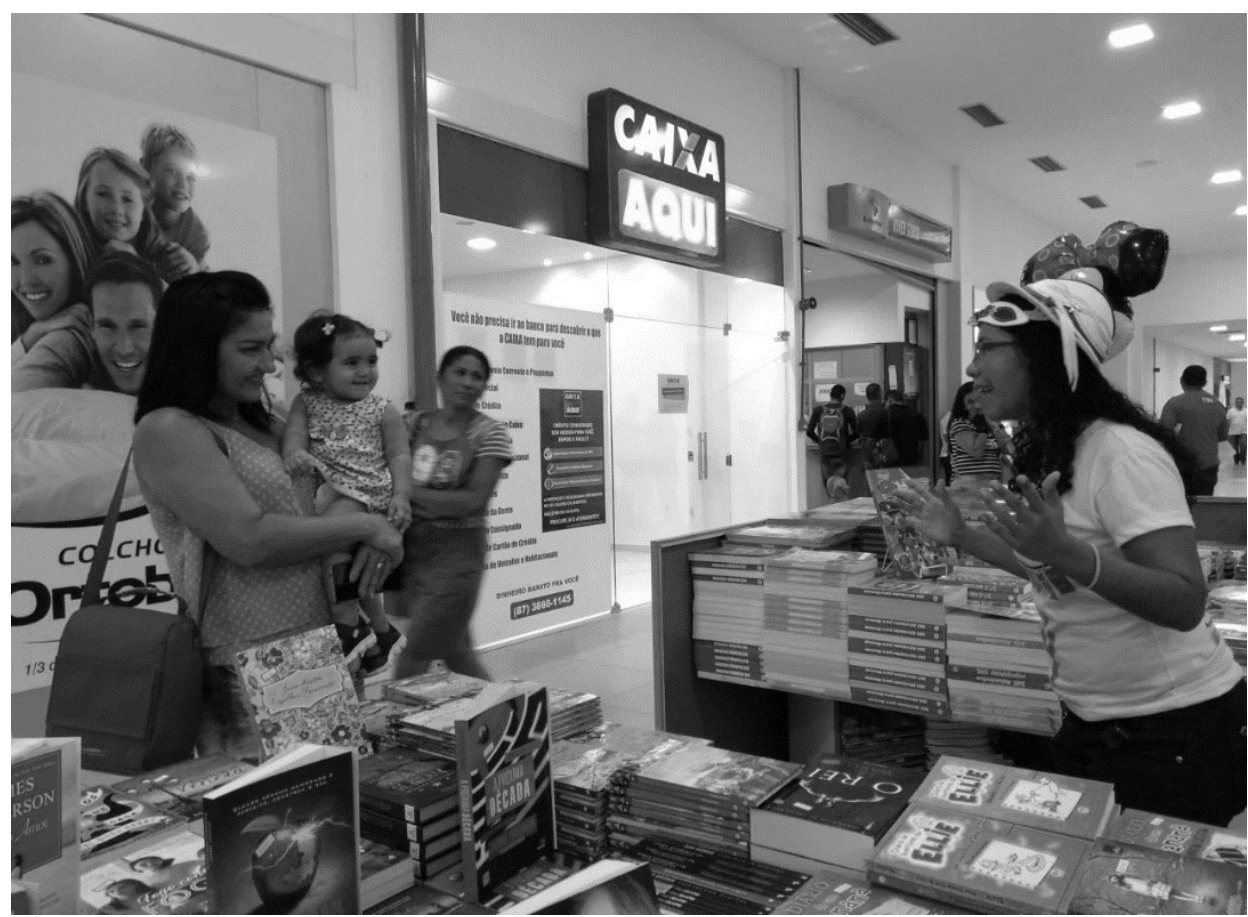

Foto: Ariane Samila Rosa

Em uma entrevista ${ }^{5}$, a presidenta do grupo, que morou em Recife, relembrou evento semelhante realizado, somente por ela, há alguns anos, em uma livraria daquela cidade, também dentro de um shopping, onde a recepção do público foi bem mais acolhedora e o serviço de segurança do shopping orientava o preenchimento dos espaços, afim de que os presentes assistissem com comodidade. Em meio a tantos desafios, alguns passantes ficaram interessados em levar para outros espaços o trabalho visto e pediram o contato do grupo, que já tem a prática de realizar oficinas de cordéis e saraus em escolas públicas do Vale do São Francisco. Boa parte dos cordéis produzidos pelo grupo também foi vendida.

Quanto à leitura de poemas propriamente dita, o recital, que se iniciou no horário previsto, começou de maneira tímida, mas perceptível para os transeuntes do shopping. A dinâmica se dava pela récita de poemas com intervalos e permutações pelos componentes do grupo. Dentre os poemas recitados, a maioria de autoria do grupo podem-se citar: Suavidade Poesia; O Brasil que eu quero; Deusa do Sertão; A vizinha que matou a cascavel; Quando o diabo não vem ele manda seus empregados, de autoria da presidenta do grupo Graciele Castro; $O$ cavalo que defecava dinheiro e Testamento

\footnotetext{
${ }^{5}$ Entrevista gravada no Serviço Social do Comércio (SESC-Petrolina-PE).
} 
de um cachorro, ambos de Leandro Gomes de Barros, e Orgulho de ser Negro, do Poeta Nascimento.

$\mathrm{Na}$ letra do último poema recitado, Orgulho de ser Negro, eram tematizadas questões raciais:

A minha madrinha de cor clara me dizia/ só é pretinho/ mas gosto muito dele/ Só é pretinho/ E então eu me perguntava/ Qual era o defeito?/ Hoje descobri que o único defeito era o seu preconceito.

$\mathrm{Na}$ construção dos versos, o poeta traz sua vivência para escrita: sendo um homem negro, morador da periferia da cidade de Petrolina, esse contexto está presente nesse em outros poemas feitos por Fabrício, que assina com o nome artístico de Poeta Nascimento. No seu poema, o Poeta Nascimento nos mostra, ao contrário do que gramática nos diz, que a conjunção (ou operador argumentativo, na semântica) mas no verso só é pretinho mas eu gosto muito dele, contrapõe argumentos que nos permitem perceber a conclusão esperada, mas não dita, de uma sociedade preconceituosa: "é pretinho (por isso) não gosto dele". A palavra 'mas' no verso abre portas para um mundo que só o negro conhece: o racismo com que se depara diariamente, até nas relações familiares.

A presidenta do grupo, conhecida carinhosamente como Graci, vem militando na literatura já há algum tempo e tem (re)inventado formas dinâmicas para que ela e seus colegas literários tenham espaço nos círculos literários da cidade. Sua luta pelo espaço e pela visibilidade, no entanto, não deixa de lado o eu-lírico de sua poesia, podendo-se constatar nos versos

Sou um ser que guardo dor/Navego na sublime solidão/Vou andar/

Ver a noite/ Abraçar as estrelas/Sentir a suavidade do vento/ Vou deixar a porta encostada/ Se quiser mudar de ideia/ Abre a porta devagarinho/ Entra de mansinho/ E deita ao meu lado.

\section{Alguns aspectos do letramento do evento}

A discussão de um evento de récita de poesias, por um grupo de autores experimentais e até iniciantes, no espaço de uma livraria de corredor de shopping, 
necessita de ser justificada em relação aos vínculos com o conceito de letramento. Que se trata de um evento, não temos dúvidas: um evento de literatura, um sarau, uma récita. Porém, em que este evento se constitui como evento de letramento, ai já cabe uma indução teórico-argumentativa. Por isso, destacamos aqui alguns aspectos:

1. O grupo é constituído por jovens que vêm experimentando a escrita literária, poética, sem vínculo estabelecido com alguma escola literária ou com algum âmbito acadêmico. O que lhes move é uma pulsão de engajamento literário mobilizado por membros que têm um pouco mais de experiência com essa linguagem, como a presidenta do grupo, Graciele Castro, que reúne experiência anterior com a literatura e com ações de recitais, como o evento aqui já mencionado, que ela protagonizou em Recife;

2. A experiência de uns anima os outros para realizar a experiência: fora do ambiente escolar e acadêmico, no contexto de ações situadas na periferia da cidade de Petrolina, como parte de um conjunto de outras mobilizações protagonizadas pelos próprios jovens: trata-se de um conjunto de práticas de letramento literário, como expressão real do conceito de letramento ideológico;

3. Uma ação no interior de um shopping center, como o relatado aqui, proporciona trocar o comodismo de trabalhar em um espaço no próprio bairro, para adentrar em espaços não convencionais, possibilitando outras estratégias de divulgação e promoção da literatura. Mas, sobretudo, promove um estranhamento nas pessoas que por ali passavam - e nos próprios poetas, que não estavam acostumados a essa proposta, sendo isso mesmo parte da construção de uma experiência. Como os dois exemplos citados sugerem, trata-se da leitura e da escrita e da experiência com a literatura atravessada pelo engajamento estético-político, fundindo lirismo e ação político-social;

4. Partindo dos significados que os sujeitos assumem ao longo de suas vidas, ou da posição que ocupam na sociedade, tais ações mediadas pela literatura constituem-se como espaço de construção de suas identidades. Nesse aspecto, a identidade e a diferença são entendidas como processo e produto de criações sociais e culturais, submetidas às relações de poder presentes em nossa sociedade (SANTIAGO; AKKARI; MARQUES, 2013, p. 38), mas também são frutos de tensionamentos que têm o campo estético da literatura como um dos potencializadores de identidades e diferenças; 
5. A experiência com a poesia, neste caso, não apenas insere os sujeitos em suas linguagens e capacita aqueles que através dela se expressam, mas também tem a possibilidade de despertar interesse pela leitura e pela escrita de obras poéticas, para além da divulgação de trabalhos autorais. Fora das "escolas" de literatura, é o "aprender-fazendo" e dando sentido ao que é feito o que ampara a noção de letramento presente;

6. Durante a entrevista, ao frisar os objetivos da feitura desse sarau, Graciele usou um ditado popular bem conhecido: "quem é visto, é lembrado" - falando da necessidade de expandir e consolidar a proposta do grupo, visando constituir alternativas de trabalho. Isso de fato aconteceu, pois a administração do shopping, ao precisar de uma arte para o período junino, contratou o serviço gráfico da poeta, que possui em sua residência uma pequena editora artesanal, chamada Cordelaria Castro. A editora publica cordéis do grupo e de quem a procurar, e fornece cordéis periodicamente para a livraria em questão, que os revende, compartilhando o pequeno lucro.

Relacionamos o evento de letramento aqui analisado ao conceito desde letramento ideológico de Street, que reconhece a natureza ideológica e cultural presente nas práticas de uso da língua escrita, neste caso, da poesia de cordel. Como se vê, há um conjunto vasto de razões no interior deste evento, sendo a prática da literatura parte de um espectro mais amplo da luta pela produção da existência, que passa pela afirmação geracional, pelo empoderamento, pelo reconhecimento, pela visibilidade e quebra de preconceitos.

Sendo parte de uma luta pelo recurso da literatura, é válido ressaltar que o grupo não possui nenhum apoio de editais, parcerias, tampouco da Secretaria de Cultura do município e/ou Estado, e promove suas ações às suas próprias custas; para comprar os equipamentos necessários, utiliza o recurso da venda dos cordéis e faz rifas. A realização das oficinas é feita de maneira voluntária.

\section{Considerações finais}

A construção de novos tipos de letramentos, interligadas ao "modelo ideológico", proposto por Brian Street (1994), está cada vez mais dinâmica. Assim, 
consideramos a construção das novas narrativas propostas pelo grupo aqui analisado, acreditando que ele consegue adentrar e propor novas perspectivas e usos sociais da leitura e da escrita, algo que está bem no centro do espírito do conceito de letramento, visto que o grupo age de forma a transcender à leitura e à escrita, interagindo outras questões do contexto social em que está inserido.

No contexto da abordagem intercultural, mesmo no estranhamento dos que passam e não estão habituados àquela performance da récita, é possibilitada a criação de narrativas em sentido oposto à cultura de massa, provocando os consumidores, presos à mera relação de compra e venda, no interior de um templo do consumo.

Isso é o que acontece com essas atividades do Projeto Ser Tão Poeta, pois, ao saírem os jovens de seu local de costume (o bairro de periferia) adentrando em um espaço com perspectivas tão diferentes, como um shopping, há um choque intercultural tanto da parte do grupo quanto da parte dos que o veem e o ouvem. Um estranhamento comum permite várias indagações - presumíveis pelos semblantes dos que passam e olham: há um espaço delimitado para cada coisa? Quem tem o poder de definir quais são os espaços da literatura, da poesia, da récita? A periferia deve ficar no seu local de origem ou pode se expressar também nesses espaços "de elite”? Atividades artísticas têm um lugar definido para acontecer, deve se acomodar aos "lugares adequados" ou ela existe para abrir trilhas e essas fendas de inquietação?

Argumentamos que todas essas circunstâncias aqui relatadas são também circunstâncias de letramento e que um evento de récita de poesias, mesmo em lugares inusitados para a literatura, como um shopping, pelos diversos aspectos que apresenta, em termos de prática de leitura e de escrita - e de uso social disso - constitui-se sim, um bom exemplo de um evento de letramento, no qual se expressam novas narrativas de letramento literário.

\section{Referências bibliográficas}

GUATTARI, Félix. As três ecologias - Campinas, SP: Papirus, 1990.

KLEIMAN, Ângela B. Modelos de letramento e as práticas de alfabetização na escola. In: KLEIMAN, Ângela B. (Org.) Os significados do letramento. Campinas: Mercado de Letras, 1995. p.15-61. 
SANTIAGO, Mylene Cristina; AKKARI, Abdeljalil; MARQUES, Luciana Pacheco; Educação Intercultural: desafios e possibilidades. Petrópolis- RJ: Vozes, 2013.

SOARES, Magda. Alfabetização: a questão dos métodos. - São Paulo: Contexto, 2018.

STREET, Brian. Práticas e Eventos de Letramento. Disponível online em: <http://www.ceale.fae.ufmg.br/app/webroot/glossarioceale/verbetes/praticas-e-eventosde-letramento $>$ Acesso em 31/10/2018.

Letramentos sociais: abordagens críticas do letramento no desenvolvimento, na etnografia e na educação. Letramento e mudança social: a importância do contexto social no desenvolvimento de programas de letramento. Trad. Marcos Bagno. São Paulo: Parábola, 2014.

. Perspectivas Interculturais sobre o letramento. Filologia e linguística portuguesa. Usp. V 018. p. 465-488. 2006. 